\title{
Dispersing of Petroleum Asphaltenes by Acidic Ionic Liquid and Determination by UV-Visible Spectroscopy
}

\author{
Eshagh Rezaee Nezhad, ${ }^{1,2}$ Fariba Heidarizadeh, ${ }^{1}$ Sami Sajjadifar, ${ }^{2}$ and Zahra Abbasi ${ }^{2}$ \\ ${ }^{1}$ Department of Chemistry, Faculty of Sciences, Shahid Chamran University, Ahvaz 61357-43337, Iran \\ ${ }^{2}$ Department of Chemistry, Payame Noor University, P.O. BOX 19395-4697, Tehran, Iran \\ Correspondence should be addressed to Eshagh Rezaee Nezhad; e.rezaee66@yahoo.com
}

Received 31 December 2012; Revised 23 February 2013; Accepted 25 February 2013

Academic Editor: Jorge Ancheyta

Copyright (c) 2013 Eshagh Rezaee Nezhad et al. This is an open access article distributed under the Creative Commons Attribution License, which permits unrestricted use, distribution, and reproduction in any medium, provided the original work is properly cited.

\begin{abstract}
Nowadays, constructing a mechanism to prevent the aggregation petroleum asphaltenes by the use of new acidic ionic liquids has become of fundamental importance. In this research, 3-(2-carboxybenzoyl)-1-methyl-1H-imidazol-3-ium chloride ([CbMIM] $[\mathrm{Cl}])$ and other ionic liquids such as $[\mathrm{CbMIM}] \mathrm{BF}_{4},[\mathrm{HMIM}] \mathrm{Cl},[\mathrm{BMIM}] \mathrm{Br}$, and $[\mathrm{HMIM}] \mathrm{HSO}_{4}$ were tested. It should be noted that during the experiment the presence of the acidic ionic liquid moiety enhanced interactions between asphaltenes and acidic ionic liquids and it greatly limited asphaltene aggregation. We considered parameters such as temperature, amount of dispersant, effect of water: toluene ratio, the stirring time and effects of other ionic liquids, and determination of concentration of petroleum asphaltenes after dispersing by acidic ionic liquid under various parameters using UV-Visible spectroscopy.
\end{abstract}

\section{Introduction}

Asphaltene is defined as a component of the crude oil which is precipitated by adding low molecular weight solvents (n-alkanes) [1]. According to recent studies, asphaltenes are defined as solid soluble asphaltenes in aromatic solvents (e.g., benzene/toluene) and are also regarded as insoluble asphaltenes in paraffinic solvents ( $\mathrm{n}$-heptane/n-pentane/ petroleum ether, etc.) [2]. Asphaltenes are petroleum hydrocarbons with extremely complex molecular structure containing sulfur (0.3-10.3\%), oxygen (0.3-4.8\%), nitrogen (0.6$3.3 \%$ ), and metal elements, such as $\mathrm{Fe}, \mathrm{Ni}$, and $\mathrm{V}$ in a small amount [3-6]. One of the most important problems in oil industries is the precipitation of heavy components of crude oil such as asphaltenes. The precipitation of these compounds causes different problems like the blockage of crude oil extraction in transport pipes and pollution of ecosystems $[7,8]$. The aromatic moiety, through $\pi-\pi^{*}$ and dipole interactions, was thought to be one of the dominant contributors to asphaltene self-association. Hence, proper characterization of the asphaltene molecular structure and its aromaticity is fundamental in understanding of the self-association phenomenon [9]. The efficiency of dispersants is dependent on their polarity and structure. Therefore, dispersants should have an affinity to asphaltenes and should either be absorbed on the surface of the asphaltene aggregation or become bond with the polar group of asphaltene molecules [10]. Recent studies show that the petroleum asphaltenes are strong hydrogen bond acceptors and weak hydrogen bond donors [11]. However, strong acids become effective asphaltene dispersants if their alkyl tails are long enough to provide the necessary steric-stabilization layers around the asphaltenes. Besides, organic salts may be strong donors of the hydrogen bonding and can be used to stabilize asphaltenes [12].

$\mathrm{Hu}$ an Guo reported the alkylpyridinium-based and alkylisoquinolinium-based ionic liquids they claimed that these cations of ionic liquids cannot have a stable bond with asphaltene and form complexes because of a low density of the cation which are delocalized from the whole head of aromatic rings [13]. Association of asphaltenes in solutions has been the subject of a number of studies, Evdokimov et al. [14-16], Sheu [17] in which The reported concentrations of aggregation were typically in the range $2-18 \mathrm{~g} / \mathrm{L}$, depending on a solvent. 


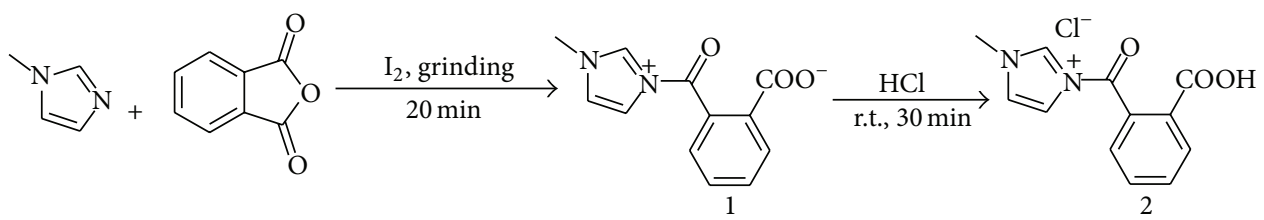

SCHeme 1: Synthesis of (3-(2-carboxybenzoyl)-1-methyl-1H-imidazol-3-ium chloride).

TABLE 1: Elemental analysis of crude oil studied.

\begin{tabular}{lc}
\hline Element & Crude oil \% \\
\hline $\mathrm{C}$ & 83.15 \\
$\mathrm{H}$ & 12.37 \\
$\mathrm{O}$ & 0.68 \\
$\mathrm{~N}$ & 0.36 \\
$\mathrm{~S}$ & 0.83 \\
\hline Total & 97.32 \\
Residue & 2.61 \\
\hline
\end{tabular}

Asphaltenes precipitation is one of the problems affecting crude oil production and refining processes. asphaltenes change a very high temperature and pressure where asphaltenes are expected to exist in a molecular form [18].

In this paper, we synthesized the acidic ionic liquid and used a great deal of petroleum asphaltenes' dispersant. In present study, we observed that the acidic ionic liquid, with the help of its hydrogen bond and electrostatic interaction, prevents asphaltene deposition.

\section{Experimental}

2.1. Chemicals and Instruments. Phthalic anhydride was provided from Merck company, and toluene was purchased from Fluka company. All solvents and reagents were used without further purification. UV-Visible spectrophotometer (Jasco model 7850), quartz cell with $1 \mathrm{~cm}$. The crude oils were from the Maroon petroleum field. The chemical composition of crude oil obtained analysis is given in Table 1. Results of SARA analysis are presented in Table 2.

2.2. Preparation of the Acidic Ionic Liquid (AIL). Acidic ionic liquid [(3-(2-carboxybenzoyl)-1-methyl-1H-imidazol3-ium chloride ([CbMIM] [Cl]) synthesized by our group in the chemical laboratory of the shahid chamran university.

Phthalic anhydride ( $14.8 \mathrm{~g}, 0.1 \mathrm{mmol})$, 1-methyl imidazole $(8.2 \mathrm{~g}, 0.1 \mathrm{mmol})$, and a catalytic amount of iodine as a catalyst were grinded for $20 \mathrm{~min}$. After completion of the reaction, a viscous liquid, which turned into a yellow solid after drying, was obtained. Then, crude product was washed with diethyl ether $(3 \times 10 \mathrm{~mL})$ to remove iodine. The obtained salt (5 mmol, $1.15 \mathrm{gr}$ ) was added to $\mathrm{HCl}$ ( $5 \mathrm{mmol}, 37 \%$ ) and stirred for $1 \mathrm{~h}$. After that, the obtained colorless ionic liquid was dried under low pressure for $4 \mathrm{~h}$ (Scheme 1). Yield: 96\%. IR (KBr): 2400-3400, 1721, 1582, 1491, 1284. ${ }^{1} \mathrm{H}-\mathrm{NMR}\left(\mathrm{CD}_{3} \mathrm{CN}\right): 14.2(\mathrm{~s}$, acidic $\mathrm{H}), 7.3-8.5(\mathrm{~m}, 7 \mathrm{H}), 3.8(\mathrm{~s}, 3 \mathrm{H}){ }^{13} \mathrm{CNMR}\left(\mathrm{CD}_{3} \mathrm{CN}\right): 35.7$,
TABLE 2: Results of the SARA analysis.

\begin{tabular}{lc}
\hline Family & W/W \% \\
\hline Saturated & 33.28 \\
Aromatics & 20.52 \\
Resins & 34.69 \\
Asphaltene & 11.51 \\
\hline Total & 100 \\
Ratio resins/asphaltene & 3.01 \\
\hline
\end{tabular}

117.44, 119.534, 123.038, 128.924, 131.04, 132.661, 135.361, 169.07, Anal. Calc. for $\mathrm{C}_{12} \mathrm{H}_{11} \mathrm{O}_{3} \mathrm{~N}_{2} \mathrm{Cl}\left(3 \mathrm{H}_{2} \mathrm{O}\right): \mathrm{C}, 44.9 ; \mathrm{H}, 5.3 ; \mathrm{N}$, 8.73\%. Found: C, 44.15; H, 4.82; N, 9.61\%.

2.3. Analysis of the Asphaltene Dispersing. UV-Vis Measurements. Determination of the asphaltene dispersing. The Dispersing of asphaltenes was determined with the use of UV-Vis spectroscopy. The spectrophotometer (Jasco model 7850 ) was operated at the wavelength of $346 \mathrm{~nm}$. The quartz cell with $1 \mathrm{~cm}$ optical path was used. Solutions of asphaltenes in toluene $\left(1 \mathrm{gL}^{-1}\right)$ were dispersed with acidic ionic liquid in water. it should be mentioned that we used asphaltene concentration with $30 \mathrm{ppm}$.

2.4. Determination of the Asphaltene Concentration in Solution after Dispersion. The absorbance of light depends on the concentration of asphaltenes in toluene solutions. The calibration curve at a wavelength of $346 \mathrm{~nm}$ was established and then used to measure the asphaltene concentration in toluene solutions. Experiments were conducted to quantify the effect of dispersants on the amount of asphaltenes remained in the solution after dispersion with acidic ionic liquid. Toluene solutions containing $30 \mathrm{ppm}$ of asphaltenes and the amount of dispersant between 1 and $5 \mathrm{mmol}$ were mixed with water at the water/toluene ratio $2: 1$. Samples were stirred during several periods of time, $1-20 \mathrm{~h}$, in the presence of several ranges of temperature $273-353^{\circ} \mathrm{K}$, and then the mixture was centrifuged and filtered on the $0.22 \mu \mathrm{m}$ Millipore filter. The concentration of asphaltenes in the filtrate was measured and compared with the initial concentration. After calculating the optimal conditions such as dispersant, time of stirring, ratio of water/toluene, and temperature. Afterwards, ionic liquids as dispersant of asphaltenes were observed/tested in the presences of optimal conditions. 


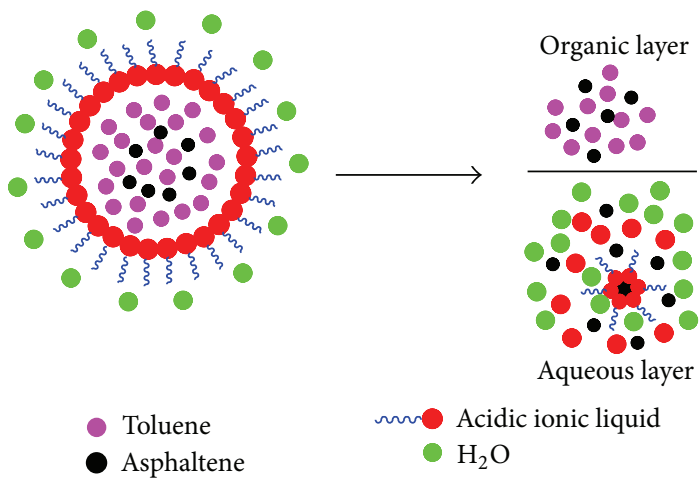

SCHEME 2: Asphaltene dispersing.

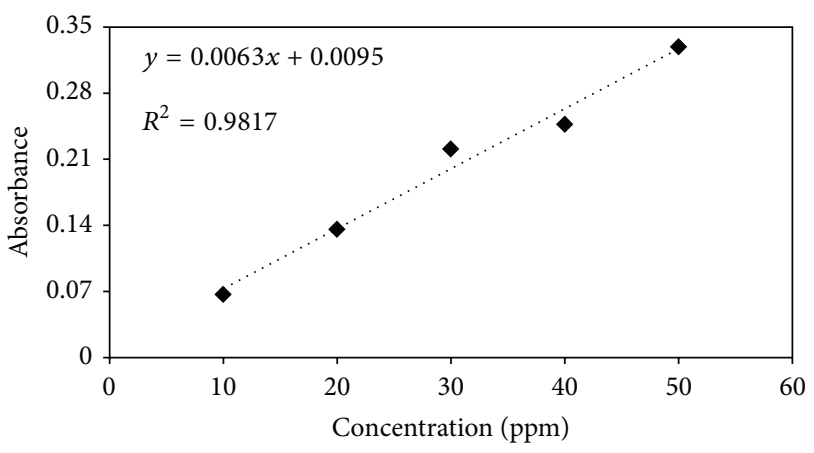

FIgURE 1: Standard curve.

\section{Results and Discussion}

Ionic liquids are also regarded as the organic salts, but because of their specific properties such as capability to dissolve various organic and inorganic compounds and potential recyclable properties, they have attracted considerable attention as ecofriendly reaction media in the green organic synthesis and may be used as asphaltene dispersants (Scheme 2).

3.1. Preparation of Standard Solutions. A $1000 \mathrm{ppm}$ asphaltene solution was prepared by dissolving $1 \mathrm{~g}$ of asphaltenes in $1000 \mathrm{~mL}$ toluene $\left(1 \mathrm{gL}^{-1}\right)$. For the preparation of standard solutions (10-50 ppm) $1-5 \mathrm{~mL}$ of primary solution $(1000 \mathrm{ppm})$ was diluted in $100 \mathrm{~mL}$ of toluene, respectively (Figure 1).

3.2. Effect Amounts of Acidic Ionic Liquid as Dispersant. Best dispersion of asphaltene depends on the amount of acidic ionic liquid. According to Figure 2 with the increase in the amount of acidic ionic liquid we have the decreases in the concentration of asphaltene in organic phase, it is so because interaction of dispersant with asphaltene increases in organic and aqueous phases. [CbMIM] $\mathrm{Cl}$ as a novel acidic ionic liquid contains carboxyl groups as well as electrostatic forces and $\pi-\pi$ interaction with polar and $\pi-\pi$ groups of asphaltene. The ionic liquid due to asphaltene deposition is from these interactions.

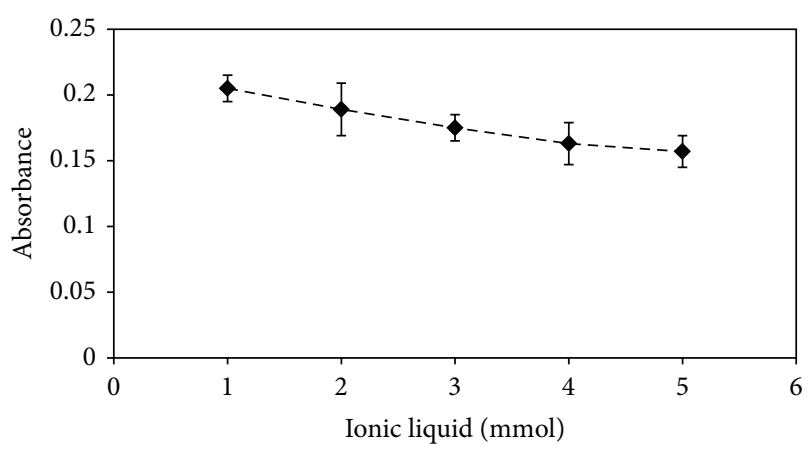

Figure 2: Effect amounts of acidic ionic liquid as dispersant.

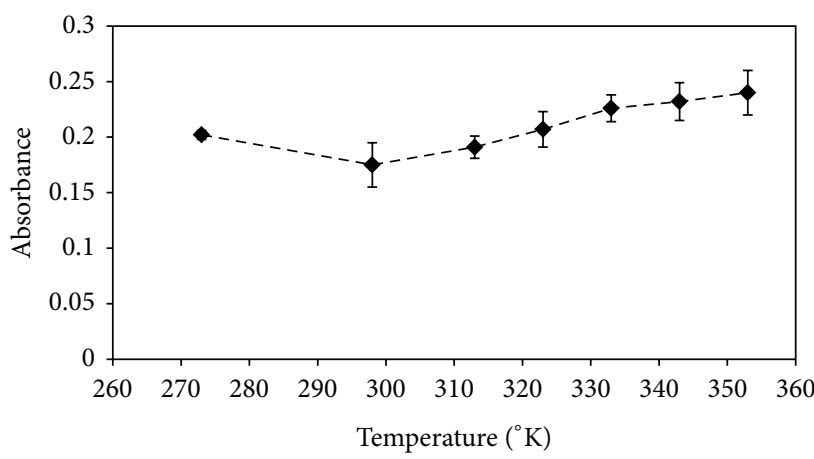

FIGURE 3: Effect of the temperature on the aggregation kinetics.

3.3. Effect of Temperature. The amounts of asphaltene precipitation have been measured at temperatures of $273^{\circ} \mathrm{K}, 298^{\circ} \mathrm{K}$, $313^{\circ} \mathrm{K}, 323^{\circ} \mathrm{K}, 333^{\circ} \mathrm{K}, 343^{\circ} \mathrm{K}$, and $353^{\circ} \mathrm{K}$. At each temperature the $[\mathrm{CbMIM}][\mathrm{Cl}]$ solution in water was used as a dispersant agent. Figure 3 illustrates the effect of temperature on the amount of asphaltene precipitation. As it is shown, the amount of asphaltene precipitation increases as temperature decreases. An increase in temperature results in the decrease of asphaltene precipitation and also less interaction between [CbMIM] [Cl] and asphaltene in aqueous phase because by increasing the temperature ionic liquids dissolve more likely in the organic phase. This data was determined by UV-Visible spectroscopy.

3.4. Effect of the Stirring Time. Samples were stirred during several periods of time, $1-20 \mathrm{~h}$, in the presence of optimal temperature, and then were centrifuged and filtered on the $0.22 \mu \mathrm{m}$ Millipore filter. The concentration of asphaltenes in the filtrate was measured and compared with the initial concentration. Figure 4 illustrates the effect of stirring time on the amount of asphaltene precipitation. As it is shown, the amount of optimal stirring time is $5 \mathrm{~h}$. the amount of asphaltene precipitation increases as stirring time increases for $5 \mathrm{~h}$ and after that it decreases.

3.5. Effect of Water: Toluene Ratio. Figure 5 reported results of the determination of the asphaltene after dispersing by [CbMIM] [Cl] using UV-Vis technique. The best dispersing 


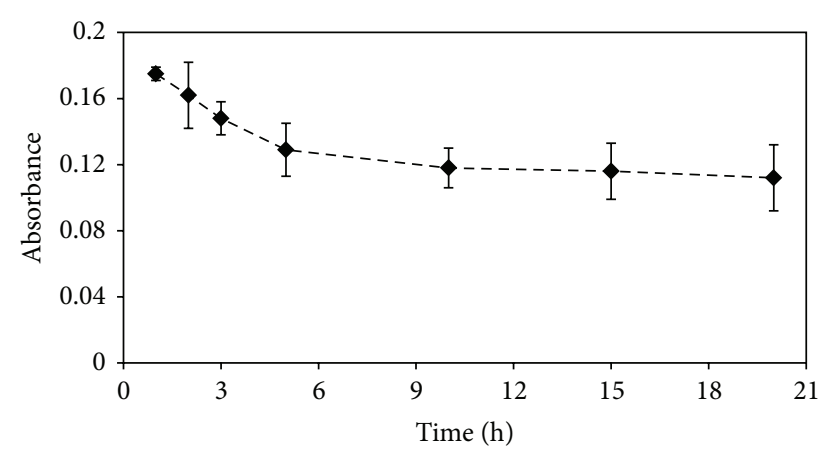

Figure 4: Effect stirring time as dispersant.

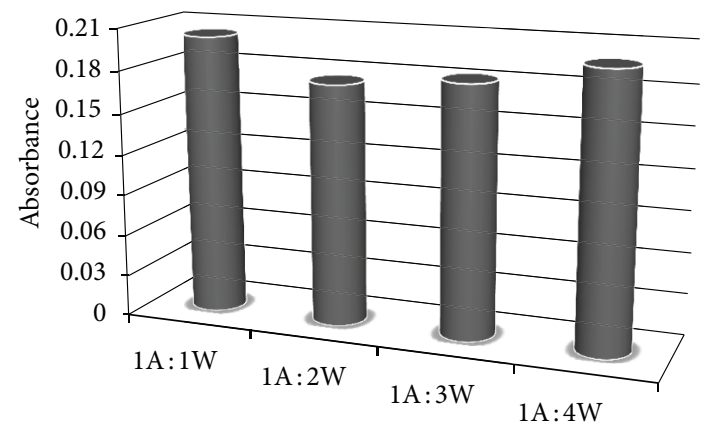

Figure 5: Effect of water: toluene ratio as dispersant ( $\mathrm{W}=$ water, $\mathrm{A}=$ asphaltenes).

of asphaltene occurs after using a value of about 2 (ratio of water and toluene volumes). In this ratio of water and toluene, high interaction between asphaltene and dispersing agent occurs.

3.6. Effect of Other Ionic Liquids. The effect of the ionic liquids (amphiphiles) is to prevent asphaltene precipitation and during this research were studied, using [CbMIM]Cl, $[\mathrm{CbMIM}] \mathrm{BF}_{4},[\mathrm{HMIM}] \mathrm{Cl},[\mathrm{BMIM}] \mathrm{Br}$, and [HMIM] $\mathrm{HSO}_{4}$. Results were compared of [CbMIM]Cl and [CbMIM] $\mathrm{BF}_{4}$ with other ionic liquids (i.e., [ILX], [HMIM] $[\mathrm{Cl}]$, [BMIM] $[\mathrm{Br}]$ and $\left.[\mathrm{HMIM}] \mathrm{HSO}_{4}\right)$. Ionic liquids are effective in most types of interactions, including dispersive, $\pi-\pi$, acidbase (hydrogen bonding), dipolar, and Coulomb interactions. After determination of optimal conditions: $3 \mathrm{mmol}$ of $[\mathrm{CbMIM}][\mathrm{Cl}]$ as dispersant, room temperature, stirring time $5 \mathrm{~h}$, and ration of water/toluene 2, a comparison between $[\mathrm{CbMIM}][\mathrm{Cl}]$ and other ionic liquids such as $[\mathrm{CbMIM}]\left[\mathrm{BF}_{4}\right]$, $[\mathrm{HMIM}][\mathrm{Cl}],[\mathrm{BMIM}][\mathrm{Br}]$, and $[\mathrm{HMIM}] \mathrm{HSO}_{4}$ (Figure 6) was done.

\section{Conclusions}

In this research, a new method for dispersing of asphaltene flocculation by the use of novel acidic ionic liquid was proposed. Acidic ionic liquid with their hydrogen bond and electrostatic interaction can be used to prevent asphaltene deposition. Finally, it should also be mentioned that we

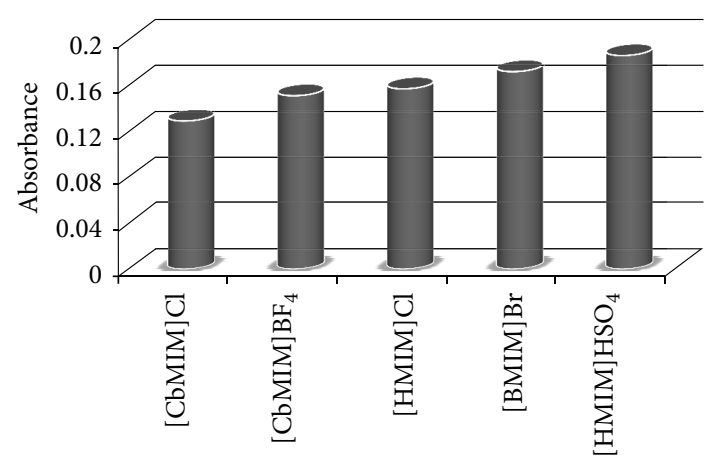

FIgURE 6: Effect of ionic liquids as dispersant.

observed and tested various parameters effective on the inhibition of the asphaltene precipitation such as temperature, amount of dispersant, the stirring time, and effects of other ionic liquids.

\section{Acknowledgments}

The authors gratefully acknowledge the financial support of this work by Shahid Chamran (Ahvaz) University Research Council and Payame Noor University of Ilam, Iran.

\section{References}

[1] M. Nikookar, G. R. Pazuki, M. R. Omidkhah, and L. Sahranavard, "Modification of a thermodynamic model and an equation of state for accurate calculation of asphaltene precipitation phase behavior," Fuel, vol. 87, no. 1, pp. 85-91, 2008.

[2] A. K. Ghosh, "Spectrophotometric study of molecular complex formation of asphaltene with two isomeric chloranils," Fuel, vol. 84, no. 2-3, pp. 153-157, 2005.

[3] L. Buch, H. Groenzin, E. Buenrostro-Gonzalez, S. I. Andersen, C. Lira-Galeana, and O. C. Mullins, "Molecular size of asphaltene fractions obtained from residuum hydrotreatment," Fuel, vol. 82, no. 9, pp. 1075-1084, 2003.

[4] H. Groenzin and O. C. Mullins, "Molecular size and structure of asphaltenes from various sources," Energy and Fuels, vol. 14, no. 3, pp. 677-684, 2000.

[5] J. T. Miller, R. B. Fisher, P. Thiyagarajan, R. E. Winans, and J. E. Hunt, "Subfractionation and characterization of mayan asphaltene," Energy and Fuels, vol. 12, no. 6, pp. 1290-1298, 1998.

[6] T. Tavassoli, S. M. Mousavi, S. A. Shojaosadati, and H. Salehizadeh, "Asphaltene biodegradation using microorganisms isolated from oil samples," Fuel, vol. 93, pp. 142-148, 2012.

[7] E. Hong and P. Watkinson, "A study of asphaltene solubility and precipitation," Fuel, vol. 83, no. 14-15, pp. 1881-1887, 2004.

[8] T. J. Kaminski, H. S. Fogler, N. Wolf, P. Wattana, and A. Mairal, "Classification of asphaltenes via fractionation and the effect of heteroatom content on dissolution kinetics," Energy and Fuels, vol. 14, no. 1, pp. 25-30, 2000.

[9] Y. Bouhadda, P. Florian, D. Bendedouch, T. Fergoug, and D. Bormann, "Determination of Algerian Hassi-Messaoud asphaltene aromaticity with different solid-state NMR sequences," Fuel, vol. 89, no. 2, pp. 522-526, 2010.

[10] M. Boukherissa, F. Mutelet, A. Modarressi, A. Dicko, D. Dafri, and M. Rogalski, "Ionic liquids as dispersants of petroleum 
asphaltenes," Energy and Fuels, vol. 23, no. 5, pp. 2557-2564, 2009.

[11] F. Mutelet, G. Ekulu, R. Solimando, and M. Rogalski, "Solubility parameters of crude oils and asphaltenes," Energy and Fuels, vol. 18, no. 3, pp. 667-673, 2004.

[12] O. León, E. Rogel, A. Urbina, A. Andújar, and A. Lucas, "Study of the adsorption of alkyl benzene-derived amphiphiles on asphaltene particles," Langmuir, vol. 15, no. 22, pp. 7653-7657, 1999.

[13] Y. F. Hu and T. M. Guo, "Effect of the structures of ionic liquids and alkylbenzene-derived amphiphiles on the inhibition of asphaltene precipitation from $\mathrm{CO}_{2}$-injected reservoir oils," Langmuir, vol. 21, no. 18, pp. 8168-8174, 2005.

[14] I. N. Evdokimov, N. Y. Eliseev, and B. R. Akhmetov, "Assembly of asphaltene molecular as studied by near-UV/visible spectroscopy aggregates, I. Structure of the absorbance spectrum," Journal of Petroleum Science and Engineering, vol. 37, no. 3-4, pp. 135-143, 2003.

[15] I. N. Evdokimov, N. Y. Eliseev, and B. R. Akhmetov, "Assembly of asphaltene molecular as studied by near-UV/visible spectroscopy aggregates, II. Concentration dependencies of absorptivities," Journal of Petroleum Science and Engineering, vol. 37, no. 3-4, pp. 145-152, 2003.

[16] I. N. Evdokimov, N. Y. Eliseev, and B. R. Akhmetov, "Initial stages of asphaltene aggregation in dilute crude oil solutions: studies of viscosity and NMR relaxation," Fuel, vol. 82, no. 7, pp. 817-823, 2003.

[17] E. Y. Sheu, "Petroleum asphaltene-properties, characterization, and issues," Energy and Fuels, vol. 16, no. 1, pp. 74-82, 2002.

[18] M. Idris and L. N. Okoro, "A review on the effects of asphaltene on petroleum processing," European Chemical Bulletin, vol. 2, no. 6, pp. 393-396, 2013. 

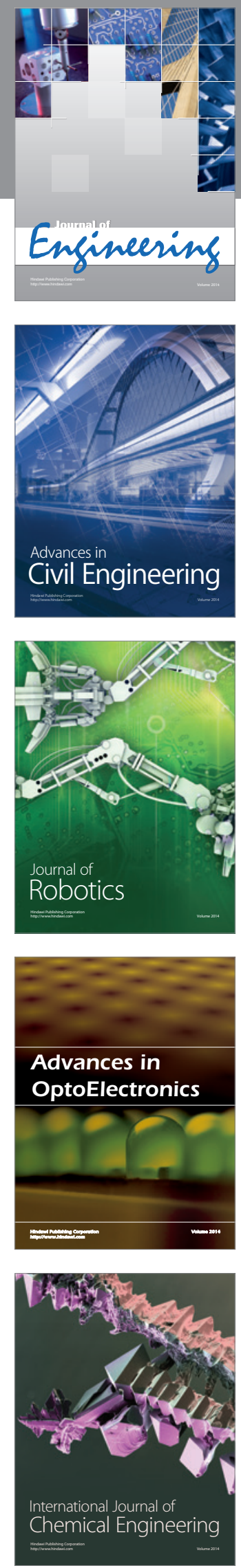

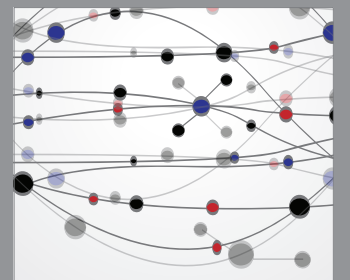

The Scientific World Journal
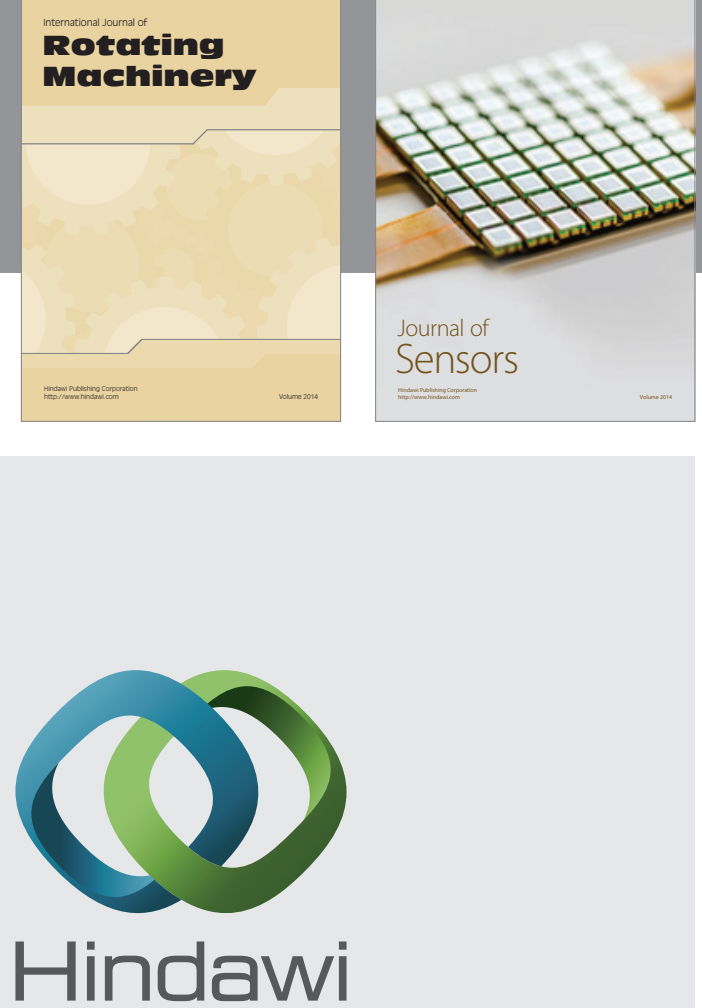

Submit your manuscripts at http://www.hindawi.com
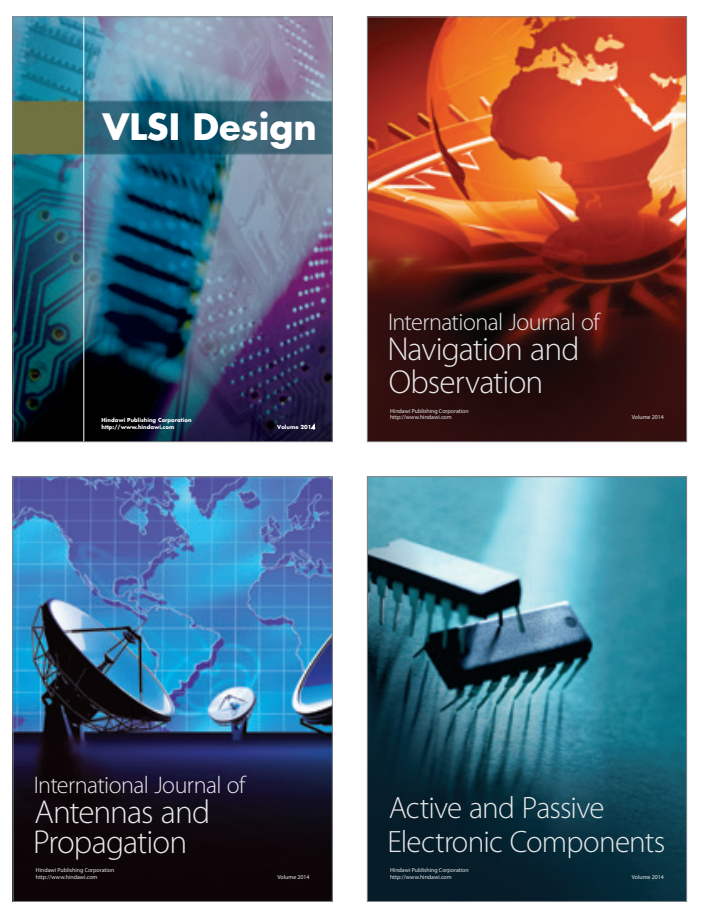
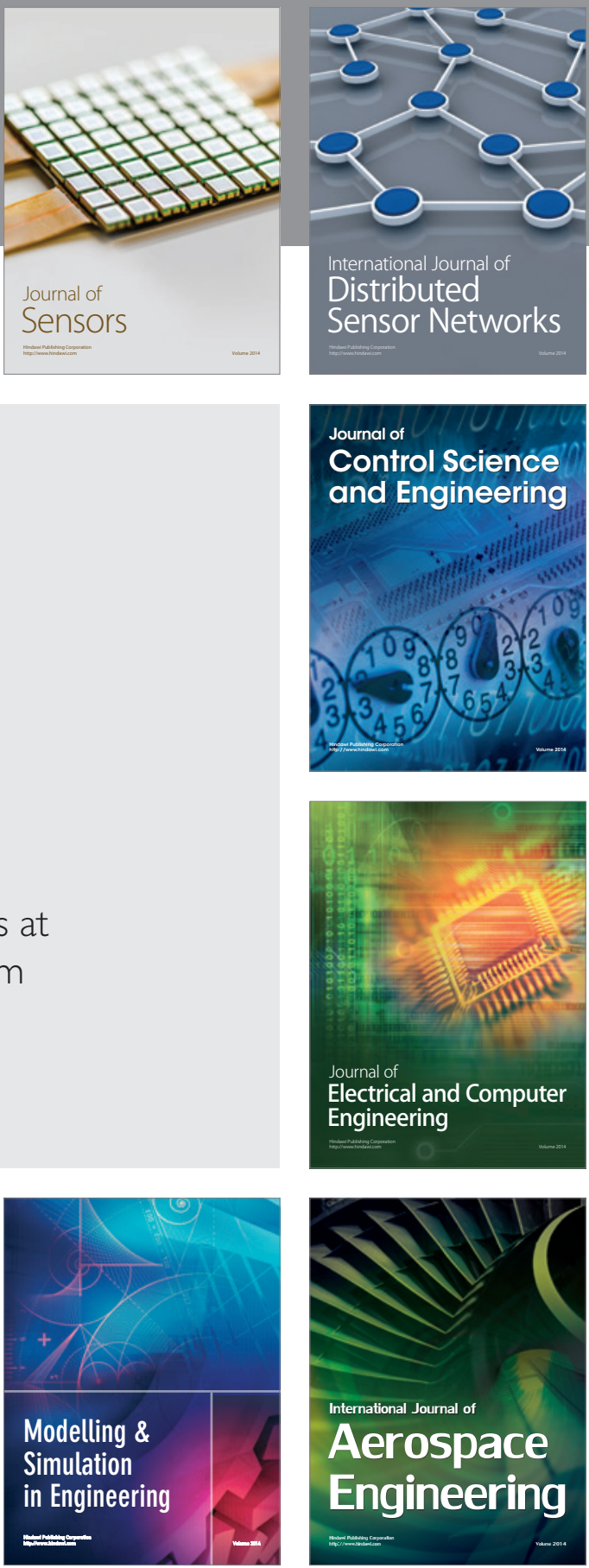

Journal of

Control Science

and Engineering
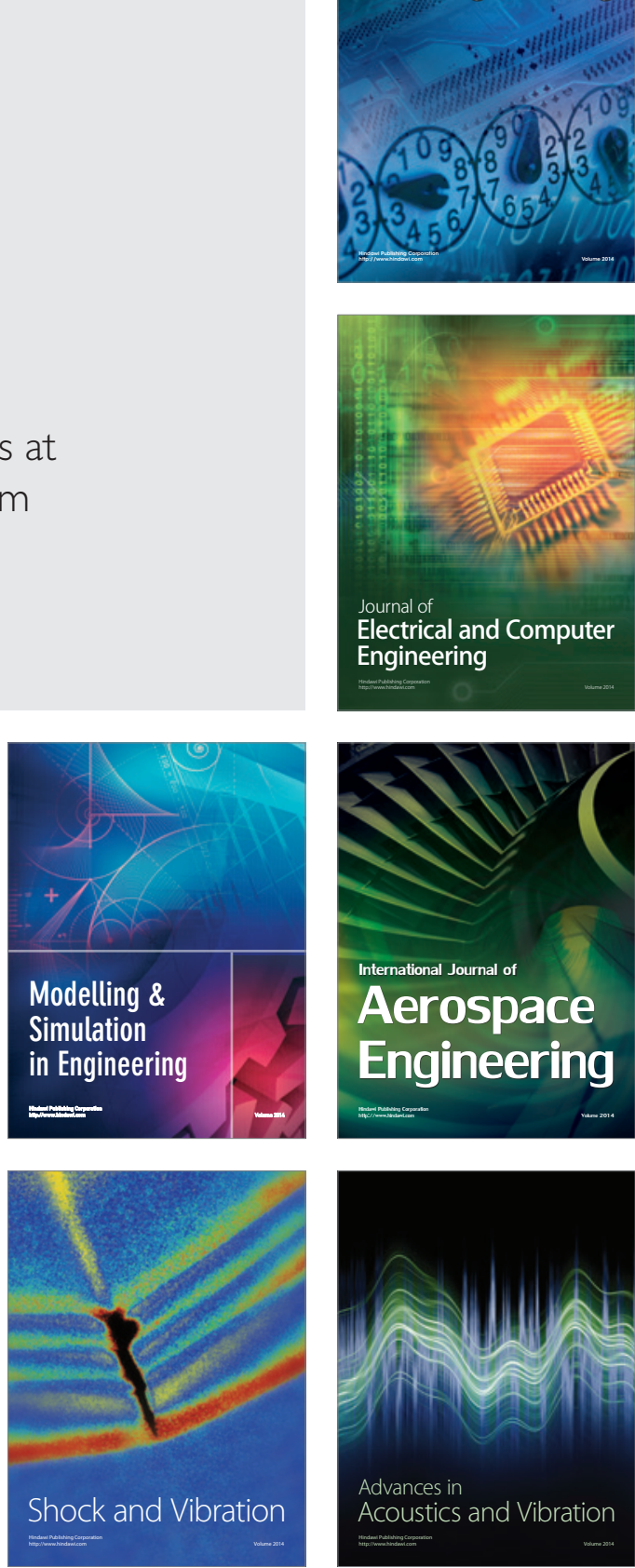